\title{
Training educational managers to use information systems: A three phase approach
}

\author{
C. L. Fulmer
}

Northern Illinois University

Leadership and Educational Policy Studies, 201 Gabel Hall, DeKalb, IL 60115, USA, (815)748-3615,p60clf1@wpo.cso.niu.edu

\author{
F. P. Frank
}

Georgia State University

Educational Policy Studies, University Plaza, Atlanta, Georgia, USA, (404)651-1199,ffrank@gsu.edu

\begin{abstract}
Training educational managers to make better use of information technology (IT) is an imperative for increasing school productivity. Recommendations for training managers in IT are culled from the literature. This article describes a three phase approach to training. Phase I focuses on IT literacy. Phase II focuses on competence with application software. Phase III focuses on building information systems and data analysis skills. The authors argue that Phase III training, a complex undertaking, should be the work of graduate management programs.
\end{abstract}

\section{Keywords \\ Professional Development, Educational Management, Information Technology}

\section{INTRODUCTION}

In this era of rapid application of technology to one's work life, school managers are not keeping pace with race car drivers or nuclear physicists. Two key questions must be asked. First, what is the state of the training school managers? Second, what training must occur to help school managers catch up with the progress of others? The three phase approach proposed in this article is based on the assumptions that managers-in-training evidence great differences in IT skills and that IT training must move them beyond IT literacy to help them become data analysts. 


\section{A REVIEW OF THE LITERATURE ON TRAINING}

The literature on training educational administrators to use information technology was organised around six topics: the rationale for training, goals of training, responsibility for training, training models, inadequacies of training models, and training recommendations. Major findings from the review are outlined in the following paragraphs.

\subsection{Rationale for training}

The following themes provide a rationale for training. If administrators are to be change agents for schools of the future, they need to understand the power and the potential of technology (Bezonian, Rancher \& Speck, 1991; Boost, 1988). The process of integrating technology with the work life of an organisation causes a mutual adaptation process for both humans and information systems (Zuboff, 1988; Crow \& Radian, 1993). The issue of training is more crucial than ever for using information systems (Fung, 1991; Bozeman \& Spuck, 1991). Current and future managers expect to use computers in their work (Fulmer, 1990). The final and most obvious theme was the lack of training experiences for educators in the use of information technology (Bosch, 1988; Visscher \& Spuck, 1991).

\subsection{Goals for administrator training}

Several themes emerged regarding the goals of administrator training. These included helping educational managers to become computer literate, to acquire knowledge and proficiency in the use of computers, to use computers as problem solving tools, to be trained in the use of information systems, and to analyse the information produced by information systems. For many (Frank, Mackett, \& Abrams, 1985, 1989, 1989; Bozeman, Raucher \& Spuck, 1991; Visscher \& Spuck, 1991; Bozeman \& Spuck, 1991; Sproull \& Zubrow, 1981) it is not enough to provide literacy training; instead, the goal is for administrators to be able to use information for decision making.

\subsection{Responsibility for administrator training}

For the most part, individuals have taken the responsibility for training themselves to use technology to support administrative functions (Bozeman \& Spuck, 1991; Visscher \& Spuck, 1991; Chang, 1990; Carl, 1983; Fulmer, 1990), were self-taught, learned by doing, or learned from other individuals, with only a few receiving formal technology training. Kearsley and Lynch (1992) suggested that universities and colleges, state, local, and other professional organisations should work cooperatively to provide this training. Turner, (1989), Elkin (1993), and Gooler (1989) blame universities for the lag in training of educational leaders.

Still others (Thomas \& Knezek, 1991) think individual states should institute certification requirements to insure the acquisition of technology skills. Swan (1993) reports that thirtyfour of the fifty United States already do. Bird (1991) and Hui and Pun (1988) argue that the local education agency must take responsibility for training. Dale and Habib (1991) conceptualise the training responsibility problem as either centralised training, regional based training or task oriented support training. 


\subsection{Training models}

Telem (1991b) has described a three prong training model: a 40 hour training program for principals, a 20 hour training program for secretaries, and peer-consultation with skilled others. User groups (Visscher, 1991; Chang, 1993) and the single computer literacy course (Kearsley \& Lynch, 1992) were two other training models. While many researchers (Visscher, 1991; Chang, 1993; Kearsley \& Lynch, 1992, Telem, 1991a; Crow \& Rairden, 1993) made suggestions or recommended strategies related to training administrators to use technology and/or information systems, three studies focused on specific training models (Bosch, 1988; Spuck \& Bozeman, 1988 and Fulmer, 1990). Spuck and Bozeman (1988) have written about sample curricula for users with little experience. Fulmer's (1990) work focused on strategies of infusing technological applications into existing courses with an administrator preparation program. Computer competencies were handled three ways: students gained competencies before entering the program, students took a course in addition to the program, or students took computer-integrated courses (a hybrid mix of content and technology). Bosch's (1988) training model consisted of cognitive and proficiency goals in a three stage approach. In stage one administrators acquired cognitive goals; in stage two they gained the proficiency skills; and in stage three administrators developed practical applications for the school district.

\subsection{Inadequacy of training models}

Another topic that emerged was the inadequacy of existing training models. Kearsley and Lynch (1992) used the words inappropriate and ineffective to describe training. Randall (1989) complained that training was too focused on computer literacy. Jacobs (1993) credited lack of training time and poor system design for training inadequacies. Dale and Habib (1991) reported that training courses focused too much on keyboard skills and data entry skills at the expense of system management and work practice issues. Visscher and Spuck (1991) suggested that training is often too technical and did not attend to how information systems support management responsibilities. Fung (1991) claimed that training was a waste of time and money. Bozeman and Spuck (1991) shared that only the phasing in of new computer using faculty will resolve the training issue at the university level. In sum, the themes that emerged can be translated as too little, too late, too unfocused.

\subsection{Training recommendations}

There were, however, positive training recommendations expressed in terms of "shoulds." The training format should be designed around the training needs of a district (Bosch, 1988). Training needs should be determined by assessing actual versus ideal computer literacy levels (Tombly, 1992). Training should be intensive, appropriate, and adequate (Visscher \& Spuck, 1991). Training activities should vary with levels of computer competence (Bosch, 1988). Motivation should be high throughout the system in order for training to succeed (Bosch, 1988). Useful training strategies should include high levels of support, documentation, and self-help user groups (Dale \& Habib, 1991). Timely on-the-job-training should be used instead of one shot pre-service training (Fung, 1991). A theory/demonstration/ practice/feedback cycle should be used in training (Fung, 1991). In training sessions, students should be required to demonstrate computer literacy (Bozeman \& Spuck, 1991). And finally, in training sessions, students should be able to demonstrate applications of computer 
technology to instruction and management functions (Bozeman \& Spuck, 1991; Fulmer \& Frank, 1996).

\section{FROM COMPUTER LITERACY TO DATA ANALYSIS}

The research is clear. Existing training efforts in academic preparation programs and other organisations are inadequate. Lieberman and Linn (1991) proposed that we rethink the training process. Many of the recommendations in the literature support the basic tenets of several learning theories: problem-based learning (Bridges, 1995), cooperative learning (Johnson \& Johnson, 1994), and experiential learning (Kolb, 1984). The call to redefine our educational leadership programs (Fulmer, 1994) requires the inclusion of multiple pedagogical models as a major design component of the training program. This means rethinking classroom organisation, the professor's role, the requirements that we impose on students, and our standards for evaluation with technology.

Data based decision making is the area in need of the most work. Neither literacy nor skill with application software is a sufficient goal. We argue that information system applications should become an integral part of general preparation instead of a prerequisite or a deficiency to the standard program. Information based data analysis requires both technical and human skills (QIP Systems, 1995). Central to this process is the development and enhancement of problem solving skills (Fung, 1991). Once we have created information systems that would hold all types of data required to inform the processes of the technical core we need to be able to ask the appropriate questions (Schuler \& Namioka, 1993; QIP Systems, 1995). If information systems are to have an impact on the technical core of educational organisations (Fulmer, 1995), IT competent educators must participate in the development of those systems.

Therefore, preparing students to use and develop information systems as tools for data analysis is what is needed to bring educational organisations and the managers they prepare up to speed with the rest of the world. To do so we are proposing a three phase training approach to competence in data analysis: Phase I - Basic IT Literacy; Phase II - IT Package Competence; and Phase III - Data Analysis and Systems Development.

\subsection{Factors that inform the three phase approach}

In thinking through the program design, we have taken four factors into account: sense of scale, competence in data analysis, flair for analytics, and prior knowledge of IT. These four factors support the inclusion of multiple pedagogical strategies and delivery models to accommodate the learning styles of learners who enter training programs.

By a sense of scale we mean that information technology and the logic which underlies its working now touches nearly every part of our every day life. Familiarity with IT is a requisite to function effectively as an educational manager. While the application of information technology is not equivalent to reading, it is analogous. When potential educational managers enter our graduate program we do not ask whether they can read, but given the importance of reading to functioning as a manager, we ask instead about the quality of their skill in reading. In effect, we hold that it is necessary but insufficient that a person can read. IT has a place in a manager's everyday work that is as significant as reading. Put simply, any person who would describe IT training in terms of a course completely misunderstands the scale of IT in the professional lives of educational managers. Managers-in-training unable to navigate a keyboard, or who have never run a spreadsheet are a liability for educational enterprises.

The second factor which influenced our thinking is the need for educational managers to 
be competent data analysts. This does not mean that educational managers should be relegated to working out data base designs, running statistics, working out analyses of qualitative data, or printing reports. However, it does mean that each manager should be a full participant in the process of data analysis. Each manager should be knowledgeable enough about the capacity of IT to facilitate data analysis in ways that might not have been possible prior to this era or which, if possible, would have been too expensive to consider. For managers to participate at this level, each must have run software and entered the logic that the software demands. For instance, race car drivers and baseball managers regularly consult with a data analyst and participate in active discussions with that analyst about what is needed and what form the data should take. It should not be inconceivable that educational managers participate in similar data-based conversations about educational processes.

The third factor is having a flair for analytic thinking. Folks who are good at this tend to have a higher degree of comfort with the technology and tend to learn more easily in an IT environment. Facility for analysis has always been a much sought after trait among potential educational managers and attempts to help graduate students develop this facility has always been part of graduate training. While this trait has been more typically evidenced as success in statistics and research courses, it has particular importance for competence in IT. Students will evidence substantial variance on this trait.

The fourth factor is having prior knowledge of IT. Students enter graduate school experience with differing levels of technology competence. While basic computer literacy is more common with each passing year, clearly there are some persons who possess only rudimentary knowledge of computing. In spite of the explosive development of IT, preparation programs in educational management have often decided against setting a computer literacy standard as an entry criterion to training programs. In part, this was justified as a fairness and access issue. For other programs, the professoriate was not aware of the need. As a result many programs also failed to set minimum technology standards for certification or degrees.

\subsection{Typology of IT learner types in educational manager programs}

Persons who seek certification as educational managers represent all types of learners. Training in IT must accommodate them all. Figure 1 shows a four quadrant design which juxtaposes analytic ability and computing competency. A Competent IT Consumer (Quadrant 1 ) is low analytic and has high computer competency. This person would tend be good at using pre-designed packages. A Consumer Designer (Quadrant 2) is high in both analytic facility and computer competency. This person would tend to be good at using pre-designed packages and developing new IT packages or applications. An Observer (Quadrant 3) is low on both analytic ability and IT competency. This person would be an observer of events. An Astute Observer (Quadrant 4) has analytic ability but low IT competency. This person would follow the logic of information technology but would not yet be a user.

\begin{tabular}{|l|c|l|}
\hline $\begin{array}{l}\text { High } \\
\text { Competency }\end{array}$ & $\begin{array}{c}\text { Q 1 } \\
\text { Competent IT Consumer }\end{array}$ & $\begin{array}{l}\text { Q } 2 \\
\text { Consumer Designer }\end{array}$ \\
\hline Low & Q 3 & Q 4 \\
Competency & Observer & Astute Observer \\
\hline & Low Analytic & High Analytic \\
\hline
\end{tabular}

Figure 1 Training types by level of computer competency and analytic ability 
Obviously, the purpose of the training program would be to bring as many persons into Quadrant 2 as possible. Moving from Quadrant 4 (Astute Observer) to Quadrant 2 (Consumer/Designer) would seem to be the easiest move from a pedagogical and personal growth perspective. Moving from Quadrant 3 (Observer) to Quadrant 2 (Consumer/Designer) would seem to be the most problematic. In this case, a person would require more time to practice and learning might take them away from their strengths or inclination. Nevertheless, given that training educational managers in IT means moving differing people differing ways in the paradigm, training programs must adapt to these learning differences. Today it is imperative that all graduates of training programs move to either Quadrants 1 or 2.

\subsection{Content of the three phases approach}

This three phase model includes much of existing training in phases I and II. The third phase of the proposed model moves programs beyond traditional training modes and includes a much neglected area of training leaders to be competent data analysts. Phase I or Basic IT Literacy includes training for components for basic information and skill development in areas such as keyboarding, operating systems, word processing, data bases, spreadsheets, graphics and presentation packages, statistics and communications including Internet. Phase II or Packaged IT Competence includes training components for skills with software packages such as scheduling, budget, space, cafeteria, inventory, test results, attendance, discipline and counselling. For each Phase I and II skill component the following decisions must be made: the need for the component, whether or not credit would be given for skill acquisition, which program stage skill acquisition is required (pre-program, program, program-exit), how skill training would be delivered (outside vendor, university vendor, or university course), and what learning strategies would be used (skill/drill, cooperative learning, user group, or problem based activities).

In Phase III or Data Analysis and System Development a manager, having mastered prerequisite Phase I and II skills, would engage in field work in school districts to develop modular components of dynamic, interactive teaching and learning based information systems (Fulmer and Frank, 1996). Work in data analysis would focus on continuing to develop tools for data gathering, data gathering, protocols for data analysis, and interaction with teachers and other educators, children and parents to continue to identify questions of importance. Students would undertake statistical analysis of data and continue to generate plausible explanations of relationships revealed by those analyses. This work in IT would draw on other content aspects of the preparation program which include organisational analysis, statistical applications, research design, and the clinical components of the program. Recommended minimum time in the field would be at least 50 hours and this work would be part of the preparation program at the post masters level.

\section{CONCLUSIONS}

A three phase training approach was described in this article. Old methods of literacy training are not sufficient for the needs of managers of today. Data analysis is required for practically every conceivable field of endeavour. Phases I and II are focused on basic literacy needs and competencies with packaged applications. Phase III, the area of greatest and most 
developmental need, is where students of IT move beyond application software into information system development and data analysis. The authors argue that Phase III is where preparation programs have the greatest potential to influence the development of more responsive information systems. Phase III, the training model of the future, will put our managers in step with the race drivers and the baseball managers of the world.

\section{REFERENCES}

Bird, P. (1991). Computer assisted school administration in England. Journal of Research on Computing in Education, 24(1), 20-40.

Bosch, K. A. (1988). A microcomputer literacy training model for school administrators. Journal of Research on Computing in Education, 20, 331-8.

Bozeman, W. C., Raucher, S. M. \& Spuck, D. W. (1991). Application of computer technology to educational administration in the United States. Journal of Research on Computing in education, 24(1), 62-77.

Bozeman, W. C. \& Spuck, D. W. (1991). Technological competence. Training educational leaders. Journal of Research on Computing in Education, 24(1), 514-529.

Bridges, E. M. (1995). Implementing problem based learning in leadership development. Eugene, OR: ERIC Clearinghouse.

Carl, K. (1983). The status of computer-based preparatory programs for school administrators. (Doctoral Dissertation, University of Nevada, Las Vegas). Dissertation Abstracts International, 45, 27A.

Chang, N. Y. (1993). The assessment of computer skills of the secondary school principals in southern California school districts. (Doctoral Dissertation, University of Southern California). Dissertation Abstracts International, 53, 2175-A.

Crow, G. B. \& Rariden, R. L. (1993). Advancing the academic information infrastructure. Journal of Research on Computing in Education, 25(4), 464-472.

Dale, D. M. \& Habib, A. G. (1991). Administrative computing in the Australian educational system. Journal of Research on Computing in Education, 24(1), 120-145.

Elkins, P. W. (1993). The effective use of microcomputers for information management as perceived by school public relations specialists and public school superintendents. (Doctoral Dissertation, Texas A\&M University. Dissertation Abstracts International, 54, 40-A.

Frank, F. P., Mackett, M. \& Abrams, P. (1989). Alternative roles for school business managers in school district educational information systems. The Journal of School Business Management, 1(3), 5-16.

Frank, F. P., Mackett, M. \& Abrams, P. (1985). Principals, microcomputers, and student achievement: A comprehensive plan for increasing student achievement in K-12 education. DeKalb, IL: School Administrator Service Associates.

Fulmer, C. L. \& Frank, F. P. (1996). Developing information systems for schools of the future. A paper to be presented at the IFIP International Working Conference on ITEM, Information Technology in Educational Management for the Schools of the Future, Hong Kong.

Fulmer, C. L. (1995). Maximising the potential of information technology for management: Strategies for interfacing the technical core of education. In B. Z. Barta, M. Telem, and Y. Gev (Eds.), Information Technology in Educational Management, pp. 1-8. London, England: Chapman and Hall. 
Fulmer, C. L. (1994). Redefining teaching and learning in educational administration. Journal of School Leadership, 4(4), 451-460.

Fulmer, C. L. (1991). Teacher education and technology: Whose job, what content, and toward what end? Thresholds in Education, 16(4), 24-6.

Fulmer, C. L. (1990). The integration of micro-computer applications in educational administration curricula. An unpublished dissertation, The Penn State University, University Park, Pennsylvania.

Fung, A. C. W. (1991). Computer assisted school administration in Hong Kong. Journal of Research on Computing in Education, 24(1), 41-61.

Gooler, D. (1989). Preparing teachers to use technologies: Can universities meet the challenge? Educational Technology, 29(3), 18-21.

Hui, Y.V. \& Pun S. W. (1988). Factor analysis of secondary school principals' attitudes toward computers in Hong Kong. Journal of Research on Computing in Education, 20(4), 360-6.

Jacobs, D. (1993). Computer-related information seeking behavior of school administrators. (Doctoral Dissertation, State University of New York, Buffalo). Dissertation Abstracts International, 54, 390-A.

Johnson, D. W. \& Johnson, R. T. (1994). Leading the cooperative school. Edina, MN: Interaction Book Company.

Kearsley, G. \& Lynch, W. (1992). Educational leadership in the age of technology: The new skills. Journal of Research on Computing in Education, 25(1), 50-60.

Kolb, D. A. (1984). Experiential learning: Experience as the source of learning and development. Englewood Cliffs, NJ: Prentice-Hall.

Liberman, D. A. \& Linn M. C. (1991). Learning to learn revisited: Computers and the development of self-directed learning skills. Journal of Research on Computing in Education, 23(3), 373-395.

QIP Systems. (1995). Total quality tools for education (K-12). Dayton, OH: QIP, Inc.

Randall, R. S. (1989). Human change: A problem during design of computing systems. Journal of Research on Computing in Education, 22(2), 160-8.

Schuler, D. \& Namioka, A. (1993). Participatory design: Principles and practices. Hillsdale, NJ: Lawrence Erlbaur Associates.

Sproull, L. S. \& Zubrow, D. (1981). Performance information in school systems: Perspectives form organisational theory. Educational Administration Quarterly, 17(3), 61-79.

Spuck, D. W. \& Bozeman, W. C. (1988). Training school administrators in computer use. Journal of Research on Computing in Education, 21(2), 229- 236.

Swan, W. W. (1993). State-supported computer technology for local school superintendents and principals. (Doctoral Dissertation, University of Georgia). Dissertation Abstracts International, 54, 398-A.

Telem, M. (1991a). A knowledge base for information technology in educational administration. Journal of Research on Computing in Education, 23(4), 594-610.

Telem, M. (1991b). Computer assisted school administration - The Israeli experience. Journal of Research on Computing in Education, 24(1), 78-90.

Thomas, L. G. \& Knezek, D. (1991). Providing technology leadership for restructured schools. Journal of Research on Computing in Education, 24(2), 265-279.

Tombly, S. B. (1992). A decision support framework for staff computer literacy training and computer resource upgrading in university administrative departments. (Doctoral Dissertation, University of Kansas). Dissertation Abstracts International, 52, 3787-A. 
Turner, J. A. (1989). Teachers-training colleges slow move to computers blamed for schools lag in integrating technology. The Chronicle of Higher Education, pp. A9-A10.

Visscher, A. J. (1991). Computer assisted school administration - The Dutch experience. Journal of Research on Computing in Education, 24(1), 91-106.

Visscher, A. J. \& Spuck, D. W. (1991). Computer assisted school administration and management: The state of the art in seven nations. Journal of Research on Computing in Education 24(1), 146-168.

Zuboff, S. (1988). In the age of the smart machine: The future of work and power. New York, Basic Books.

\section{BIOGRAPHY}

Professor Fulmer earned her $\mathrm{Ph}$. D. in Educational Administration at The Pennsylvania State University, University Park, Pennsylvania, USA. Currently, she is an Associate Professor in the Department of Leadership and Educational Policy Studies at Northern Illinois University and serves as the Faculty Chair for the Educational Administration and School Business Management program. Connie's research has focused on redefining teaching and learning environments to include pedagogical-based processes and the integration of technology into educational administration curricula.

Professor Frank earned his Ph. D. in Education Administration at the State University of New York at Buffalo, New York, USA. Currently, he is Professor in the Faculty of Educational Leadership and Chair of the Department of Educational Policy Studies at Georgia State University, Atlanta, Georgia, USA. Fred's research has focused on the development of school based information systems and data analyses for educational decision making in teaching and learning environments. 